\title{
Adversarial Argument, Belief Change, and Vulnerability
}

\author{
Moira Howes $^{1} \cdot$ Catherine Hundleby ${ }^{2}$ (]) \\ Accepted: 11 September 2021 / Published online: 16 October 2021 \\ (C) The Author(s), under exclusive licence to Springer Nature B.V. 2021
}

\begin{abstract}
When people argue, they are vulnerable to unwanted and costly changes in their beliefs. This vulnerability motivates the position that belief involuntarism makes argument inherently adversarial (Casey, Informal Log 40:77-108, 2020), as well as the development of alternatives to adversarial argumentation such as "invitational rhetoric" (Foss and Griffin, Commun Monogr 62:2-18, 1995). The emphasis on involuntary belief change in such accounts, in our perspective, neglects three dimensions of arguing: the diversity of arguer intentions, audience agency, and the benefits of belief change. The complex impact of arguments on both audiences and arguers involves vulnerabilities related to various forces of argument, not just the intellectual force of premise-conclusion complexes. Shifting emphasis from adversariality to vulnerability, we propose a more holistic understanding of argument, in which vulnerability reveals various sources of strength and opportunity in addition to risk.
\end{abstract}

Keywords Adversariality $\cdot$ Argument $\cdot$ Audience $\cdot$ Belief involuntarism $\cdot$ Doxastic involuntarism $\cdot$ Persuasion $\cdot$ Speech act $\cdot$ Vulnerability

\section{Introduction}

Argumentation theorists tend to assume that arguers' contradictory or contrary starting positions provide the source of the adversarial quality that arguments can have (Govier 1999; Aikin 2011). Recently, John Casey (2020) builds an alternative case for the structural adversariality of argument by considering how reasoners may lack direct control over their own beliefs, a view known as "belief involuntarism" or "doxastic involuntarism". Because of this longstanding epistemological view, Casey indicates that audiences have only indirect influence over their beliefs and that at the same time arguers may directly influence audiences through the speech act of arguing. This suggests to Casey an intrinsic adversarial interaction between arguer and audience, to which arguer intention to change audience beliefs and the costs of change each contribute. In Casey's view, the structural features of arguer interaction relating to doxastic involuntarism

Catherine Hundleby

hundleby@uwindsor.ca

Moira Howes

mhowes@trentu.ca

1 Trent University, Peterborough, Canada

2 University of Windsor, Windsor, Canada make all arguments adversarial, whether their purpose lies in persuasion or some other end. Notably, Casey's structural adversariality does not imply that arguments must involve ancillary features that often accompany adversariality, such as aggression, anger, explicit competition, or eristic orientiations. Rather, structural adversariality means that all arguments are adversarial in a very minimal, basic sense; indeed, they may not seem adversarial at all. Structural adversariality can be quite harmless in Casey's view: it is simply part of what it is for something to be an argument and as such, argument may be adversarial yet lack features commonly associated with adversarial argument, such as insistent, forceful persuasion, explicit competitiveness, or eristic behaviors and attitudes. These additional features of adversariality may be incorporated into the basic underlying adversarial structure, but there is no necessity that this occur.

Casey's position provides an important vantagepoint for considering the relationship between adversariality and belief change, along with the question of how arguers and audiences may be vulnerable during argument and persuasion. For instance, Casey's account provides another way to make sense of the concern that adversarial argumentation can be imposing even when not explicitly oppositional, coercive, dominating or aggressive. Feminist accounts of adversarial argument, such as those of Burrow (2010); 
Govier (1999); Hundleby (2013), and Rooney (2010), outline various associations between adversariality and aggression, dominance, and inflated authority. These accounts further acknowledge that such behaviours and characteristics may arise from the attempt to impose beliefs on others such that they experience involuntary belief change or epistemic effects such as uncertainty and confusion. Indeed, concerns about the imposition of belief on others may mean that even a very minimal, structural adversariality is potentially harmful. Though these feminist accounts diverge as to whether some minimal degree of adversariality must be inherent in the structure of argument, they unite in recognizing epistemological and ethical problems with adversariality that relate to vulnerability. Feminist rhetorical perspectives cite similar concerns but tend to focus on persuasion insofar as it can involve imposing or oppressive ways of affecting others (Gearhart 1979; Foss and Griffin 1995; Fulkerson 1996; Bone et al. 2008). ${ }^{1}$ To address concerns about rhetors imposing belief change and enacting dominance during persuasion, Foss and Griffin (1995), propose an alternative, "invitational rhetoric," to reduce vulnerabilities associated with adversariality. ${ }^{2}$

Given Casey's location of adversariality as part of involuntary belief change, and feminist argumentation and invitational rhetoric's concerns with forced or coerced belief change in persuasion and argument, we focus on the question of whether adversariality provides the best (or indeed, only) way to characterize consequent belief change. By "argument" and its cognates we refer broadly to the expression of reasons, which is in keeping with Casey's "sharing reasons" (2020), Robert C. Pinto's "offering premises or evidence" (2009) and "making reasons explicit" (2010), as well as Jean Goodwin and Beth Innocenti's "making reasons apparent" (2019). We agree with Casey that attention to the speech act reveals a general potential for involuntary belief change but consider that this phenomenon can be identified most clearly in persuasive argument. We contend that Casey does not succeed in showing that offering reasons has an inherent adversarial structure, but only a possible one. We aim to show that the identified vulnerability of the audience to the arguer cannot be described as necessarily adversarial. By offering a fuller account of the vulnerabilities at play in argument, we find a smaller role for the interactive adversariality Casey identifies and point towards a more variegated account of argument interaction that includes adversarial

\footnotetext{
${ }^{1}$ Popular psychology even describes persuasion as involving "weapons" (Cialdini 2007).

2 Michael Gilbert's “coalescent argument" (1997) also offers an alternative in having arguers seek points of agreement, but arguers still start with opposed positions.
}

and non-adversarial dimensions and addresses the agency and vulnerability of both arguers and audiences.

To start with, section two outlines Casey's view that the involuntariness of belief change makes arguing adversarial and challenges the claim that audiences are largely "acted upon" in the process of belief change as well as the framing of intellectual force in terms of adversariality. To do this, we consider arguer intentions and control along with the costs and benefits of belief change. We point out a different view of the audience in section three, drawing on Foss and Griffin's (1995) account of invitational rhetoric. This model of rhetorical interaction aims to provide a liberatory alternative to forms of adversarial persuasion involving compelled belief change and the harm it may do. It helpfully draws our attention to arguer and audience vulnerabilities with respect to belief change. We find that invitational rhetoric advances understanding of audience agency considerably, but it also conceives belief change in terms of adversariality and so insufficiently explores the involved vulnerability. In section four, we thus consider the matter of vulnerability in adversarial and non-adversarial forms of argument, attending to the vulnerabilities of both arguers and audiences. Arguers and audiences share vulnerabilities to change, adversity, and adversariality arising from their universal ontological dependency as social and biological beings. Additionally, both arguers and audiences have situational vulnerability arising from the content and context of particular arguments. We then draw upon a compathetic norm of argument (Cohen and Miller 2016) to advocate a more holistic conception of the intellectual and other forces at play. We conclude that developing an account of vulnerability in argument and linking it with a compathetic approach can improve how we understand belief involuntarism and adversariality. Sharing reasons in a complex field of vulnerabilities involves interaction between audiences and arguers that is only sometimes adversarial.

\section{Adversarial Interaction}

Casey (2020) makes a case that argument is intrinsically adversarial because during argument interactions "one arguer attempts to exercise control over the beliefs of another arguer" (p 80). The arguer stands to prevail and so to frustrate and compel the other arguer in their role as audience because of doxastic involuntarism. The thesis of doxastic involuntarism, that reasoners may engage in forms of reflection that they predict will help them to gain or lose certain beliefs, when applied to argumentation suggests that even extremely careful audiences have only limited control over their own belief change; they cannot directly make themselves gain or lose beliefs. As elsewhere, in argument, reasoners seem able to only change their beliefs via an "indirect 
voluntarism." Casey contends that arguers impose beliefs on each other and that doxastic involuntarism makes all arguers intrinsically vulnerable to this imposition from other arguers and, therefore, "agreement, consensus, and collaboration can function as means of control, manipulation, or domination" (p 104). Thus, argument has an intrinsically adversarial structure whether or not arguers initially disagree.

Casey's grounding of adversarial argument in doxastic involuntarism offers a new version of minimal adversariality, one that departs from Trudy Govier's (1999) original account. Govier argues that adversariality plays an inherent role in the expression of reasons or commitments when the intention is to persuade others rationally. This minimal adversariality contrasts with what she terms "ancillary adversariality", which involves the sorts of aggressive, anxious, or fearful feelings, motivations, and behaviors that only sometimes arise when arguers attempt to compel each other to adhere to claims. Casey takes Govier's attention to the use of reason to compel others a step deeper, psychologically speaking, by moving the minimally adversarial relationship from reasons and commitments to beliefs. Casey's account of intrinsic adversariality in terms of involuntary belief change rests on three principal claims: first, arguers intend to change each other's beliefs; second, arguers have direct control over audience beliefs, while audiences have only indirect control over their beliefs; and third, changing beliefs is costly. These factors converge in the act of sharing reasons in a way that gives the interaction itself an adversarial structure.

The significance of Casey's account of structural adversariality derives in part from its resolving an ambiguity between "relations of beliefs" (80) and "relations of propositional commitments" (80) in Govier's account of minimal adversariality. Casey says:

The difference is a critical one because, plausibly, you have direct, voluntary control over your commitments but not your beliefs. More significantly, beliefs have significant costs associated with their formation, preservation, revisions, and extinction. Furthermore, beliefs can be significant parts of one's identity, and so, altering them, even through rational argument, constitutes a significant intrusion on the autonomy of another person (80-81).

Although Govier does not distinguish between beliefs and commitments in her account, Casey makes the case that her version of minimal adversariality only applies to adversariality regarding commitments. Casey observes further that critiques of minimal adversariality, such as those of Rooney (2010) and Hundleby (2013), target Govier's reliance on commitments, noting correctly that there are non-adversarial epistemic notions such as inconsistency available to identify and correct problematic relations between commitments.
There remains no need for the adversarial characterization. Thus, Govier's conclusions about the intrinsic nature of minimal adversariality do not follow from the view that arguers press audiences to change their commitments. Casey argues, however, that when one understands that arguments by their very nature cause belief change in the audience, the structurally adversarial nature of argument is evident. While critics such as Rooney and Hundleby are therefore correct that minimal adversariality does not follow from Govier's account, they are mistaken to conclude that argument is not essentially adversarial: arguments are always at least structurally adversarial.

Although Casey convinces us of the real and significant possibility of structural adversariality in many instances of argument, we find a more limited scope for adversarial interaction in general. Part of the reason for this more limited scope concerns a metaphysical issue with the thesis of doxastic involuntarism, insofar as "belief" is a folk psychological term covering complex neurological and psychological processes such that involuntarism may not always pertain; in particular, belief change during the dialectical processes of arguing seems a likely exception to the rule of doxastic involuntarism. Our concern is that each dimension of arguer interaction in Casey's account involves relational and argumentative complexity that undermines the idea that adversariality is inherent to the structure of argument. In Sect. 2.1, we focus on arguer intentions to control audience beliefs and audience control over their own beliefs. We find that arguer intentions are more varied, and audience control more direct, than on Casey's account. In Sect. 2.2, we address the view that belief change is costly. We consider the costs of belief change both synchronically (at the time of argument utterance) and diachronically (aftereffects). We find that while belief change can be costly initially, often it is not meaningfully so; moreover, it often reaps substantial rewards over time. In Sect. 2.3, we question whether the observed occasional involuntary effects of argument on the audience can be properly characterized as adversarial.

\subsection{Arguer Intentions and Audience Responses}

Casey's first reason to treat argument as adversarial concerns how arguers intend to affect an audience's cognition. He says that "all arguments involve attempting to compel others to believe something" (p 102) and explains that "offering arguments, after all, is the means of producing, maintaining, heightening, or extinguishing those beliefs in others". (p 103) Arguers in their role as audience lie at the mercy of other arguers who might influence their thinking. Casey says:

I expose you to evidence that gives you no voluntary option but to change your mind. Naturally, you have to 
grant me access to your belief system, but this is part of what is involved in agreeing to argue or agreeing to hear evidence. (Casey 2020, p 98)

At best, audiences have only indirect control over their own belief contents.

There are two initial difficulties with this view. The first concerns arguer intentions. The psychological assumption that arguers attempt to compel others to change their beliefs only sometimes holds. It applies mostly when they intend to persuade the audience of the conclusion. But arguers have various purposes for expressing reasons. Consider, for example, Marianne Doury's (2012) analysis of people in a Paris shop sharing why they agree with a new parking law. On Casey's account, the Parisians reinforce each other's beliefs about the law and so intrude on or manipulate each other's cognition even though they do not disagree ( $p$ 98, pp 101-102). Doury rejects this (Perelmanian) approach, however; and instead notes three other likely doxastic and non-doxastic motivations. The first lies in establishing a relationship with other people, a goal for arguing that Michael Gilbert (1997) calls a "face goal" (p 67). Second, Doury finds the Parisian shoppers exhibit motivations of a cognitive sort that include maieutic or heuristic effects, goals of "tracing the boundaries and examining the limits of a position that is being elaborated as the discussion unfolds" (2012, p 108). Finally, Doury observes motivation to create and sustain social identities of the sort that Debra Schiffrin (1984) and Tempest Henning (2018; 2021) also recognize in Jewish and Black African American argument practices, respectively.

Jean Goodwin and Beth Innocenti (2019) provide further evidence that intentions to gain adherence to the argument's conclusion may not account for arguers' motivations to express reasons. They draw from an example involving women's rights advocates who used arguments for women's suffrage even when they had no expectation of changing anyone's mind about suffrage. Elizabeth Cady Stanton, among other arguers at the time, recognized that women's suffrage would remain implausible to some audiences, but expressing arguments favouring suffrage allowed them to exhibit the good use of reason by women. The deliberate intentions behind an argument thus need not involve changing the audience's relationship toward the conclusion, Goodwin and Innocenti demonstrate, either in terms of the audience's cognitive attitude or in terms of the audience's outward behavior, say in expressing acceptance, and such considerations weaken Casey's claim that arguing must involve the intent to affect the audience's belief.

The second difficulty with Casey's view concerns the claim that audiences have only indirect control over their belief contents during argument. Casey limits audience agency over their own beliefs to their consent to argue or to listen to the arguer. In our view, however, the exchange of reasons provides a cognitive environment in which the audience may exercise maximal control over their own cognition. In arguing, audiences actively control the influence of external stimuli on their thoughts, including provisionally accepted claims, commitments, and beliefs. This happens in a variety of ways.

Consider, for example, the distinctive agency of the audience that factors into Robert C. Pinto's well-known definition of persuasive argument as an "invitation to inference" (2001, p 37). In this account, to accept an arguer's invitation "is a matter of drawing the 'inference' which the argument invites" (2010, p 233). The audience must follow the line of reasoning in their own way, a process that involves at least a degree of self-awareness and questioning. In Pinto's view, "belief transitions not open to the influence of critical reflection are not inferences in the full sense of the word" (2001, p 43).

Such considerations lead Pinto to reject causal theories of inference favoured by earlier argumentation scholars and which also appear to underpin Casey's view. The causal view that persuasive arguments work by causing an audience's adherence to a conclusion does not bear up, Pinto argues:

imagine a situation in which the presentation of an argument caused assent to its conclusion but in which the addressee did not make an inference from the argument's premisses to its conclusion. For example, the argument is actually too complicated for the addressee to follow, but worn down by its length and caught up by the arguer's charm, the addressee's resistance to the conclusion disappears. Would we count this as a case in which the addressee was persuaded by the argument to accept its conclusion? Caused, yes. But not, I maintain, persuaded (2001, p 37).

The causal force of expressing reasons does not always amount to persuasion. Causal theories, on Pinto's account, also need to discern some unique force connected to the inference, the tide generated by the inferential strength of an arguer's premise-conclusion complex, the momentum identified by Goodwin and Innocenti (2019) as the "intellectual force" of an argument. Attempts to isolate such forces have failed and even the most common intellectual forces, simplicity and explanatory coherence, remain uncodified. Pinto adds that only deductive reasoning has any hope of ruling out psychological and contextual influences on how audiences draw their own inferences and yet "the abstract structures that classical logic studies just don't coincide with the factors that make arguments logically good" (2001, p. 38).

Most if not all of the ways that audiences ordinarily draw inferences depend on other influences, such as social 
hierarchies and institutional structures that may indeed pit people against each other as adversaries, or arguers' and audiences' unique psychologies, histories, and personal interests. Audiences also retain significant interpretive license and the logical dimension of argument strength is not easy to actually isolate in real reasoning, as anyone knows who has tried to set exercises for a critical thinking course. The forces arguers employ and audiences experience are not just intellectual but can be social or conventional; or they may be pragmatic, "generated just by making utterances and the commitments, obligations, responsibilities, and the like undertaken in the course of making the utterances" (Goodwin and Innocenti 2019, p 671). Arguments of any interest are open to interpretation and so textbook authors often have to resort to artificial examples to minimize the range of likely interpretations (Hundleby 2010). Thus, there are various influences on argument reception aside from arguers. These various influences converge in an ecology of argument forces, one that indicates the need for a holistic account.

As part of the dialectical process of arguing, audiences can even take the step that makes all the difference in changing their own minds. Consider, for example, that an arguer, Pisces, is trying to convince Gemini to take up swimming, knowing that Gemini is looking for a new exercise routine. Pisces offers all manner of reasons in favour of its benefits. Gemini responds with questions, one of which includes whether it is possible to listen to music while swimming. If Pisces' answer is a surprising "yes," then that may be the clincher for Gemini. But was that Pisces' persuasion? Their agency? Gemini identifies the critical premise and points it out to the arguer. In such a case the agency does not seem to be purely one way or the other. Gemini very much decided that Pisces was correct, but was not passively transported by the intellectual force of Pisces' reasoning.

Another reason to think that audiences actively control the influence of external stimuli on their thoughts during argument lies in the relative ineffectiveness of argument as a means of persuasion. J. Anthony Blair (2020) observes, for example, that non-argumentative means of persuasion often prove most effective: advertisers rarely use arguments in their persuasion; similarly, religious sects inculcate beliefs in children through storytelling, social and emotional control, and other non-argumentative means ${ }^{3}$. Pinto recognizes further that reasons affect a variety of attitudes in the audience that are conscious but not specifically cognitive in the way of

\footnotetext{
3 Blair also notes, like Casey, that changing one's beliefs is cognitively costly, but whereas Casey maintains that cognitive costs make arguments adversarial, Blair observes how astonishing it is that any arguer ever successfully manages to persuade anyone given these costs. Blair and Casey's divergent conclusions from the same set of considerations make clear that weighing the costs of cognitive change and applying this to belief change is difficult and complex.
}

beliefs, doubts, or questions. Such attitudes include "reasons for wanting this or that to be the case, reasons for choosing one or another course of action (i.e., forming an intention to engage in that course of action), reasons for fearing, reasons for hoping, reasons for preferring one thing over another, and so on" (Pinto 2009, p 269). Robert Nozick (1981) argues similarly that the way an audience adjusts their beliefs in response to a persuasive argument will depend in part on what they want to be true, which need not be a bad thing because an audience can learn about the prospects that their desires might be true by reflecting on them in light of a good, related argument. Furthermore, audiences have both incidental and dispositional epistemic feelings, such as those of doubt and certainty, and in regard to an argument these feelings will play a role in uptake of the arguer's claims and be affected by them. Such dispositions and their influence on audience uptake of premises and conclusions tend to lie beyond an arguer's direct control.

Audiences also have choices between and beyond provisional impersonal commitment and fully-fledged sincere belief. They may adjust their degrees of belief or merely open themselves to the possibility of belief (Ichino 2015; Goodwin and Innocenti 2019) and, since Casey recognizes that such minor shifts in doxastic attitudes and even confirmation could be part of arguer intention, perhaps the account of interactive adversariality could be figured in terms of credences. However, arguers also may accept a conclusion with reluctance; or, they may begin to hope that the claim is true, as seems to be the case with enthusiasts who offer wide open minds for conspiracy theories (Ichino and Räikkä 2020). Such non-doxastic attitudes constitute effects in their own right and operate as conditions that influence how audiences adjust their beliefs and attitudes. Nozick comments that a philosopher persuaded by an argument to infer "a conclusion ... rejected until now ... may accept this conclusion, or reject one of the previously accepted premises, or even postpone a decision about which to do" $(1981, \mathrm{p} 2)$. The previous error may reside anywhere in the set of premises, the sources of premise support, the calculated weight of the inference, or in the formulation of the conclusion, and these components may be variously attached to non-doxastic attitudes. The interplay of doxastic and non-doxastic attitudes receives further exploration in Sect. 4 as these become understood as aspects of vulnerability.

A final example of the control audiences exert over their beliefs in argument concerns their ability to question the arguer and control the direction and duration of the argument (Walton 2005, 2011; Hundleby 2020). Arguers, even speechmakers, face questions from audiences, whether on the platform or elsewhere, and this questioning constitutes part of the argument. When the questioning ends also depends on the audience: an arguer who abandons the discussion before satisfying the audience's questions about the reasoning has 
failed to finish the argument. Moreover, arguments often end when the audience declares it, when unpersuaded, uninterested, or if they wish to avoid engaging, acquiring, or losing certain understandings. They may also decide to seek other influences. Arguer-audience dialogue, not arguer oratory, provides the typical pragmatic context for arguing. ${ }^{4}$

In sum, the vagaries of arguer intentions cast doubt on whether arguers directly change the beliefs of the audience in all or perhaps even the majority of cases. Additionally, the agency of audiences complicates Casey's relation of belief involuntarism to adversarial argument. The many ways that audiences exert agency in the course of argument casts doubt on the frequency of involuntary belief change. The risk that one may have their beliefs changed involuntarily by arguing provides uncertain grounds for any claim about the inherent, structural nature of adversariality in argument. There are reasons to think the risk is low. The logical force of reasons may be one of the least effective ways to affect the audience's thinking, especially if not closely guided by the audience themselves. The many ways that audiences may respond, including directing discussion and evaluating reasons - their own and those of other arguers-suggest that expressing reasons only very occasionally leads to involuntary belief change in others.

\subsection{The Costs and Benefits of Belief Change}

Casey's second reason for finding adversarial interaction intrinsic to the expression of reasons lies in the "significant costs associated with [the] formation, preservation, revision, and extinction [of beliefs]" (2020, p 81). Casey finds that the "indirect voluntarism of believing" means that believing involves "effort and uncertain results" and risks "exposure of weaknesses in one's position, the exacerbation of disagreement, and emotional damage to participants" (p 102). Moreover, even though there may be rational gains, revising beliefs is "difficult, and we are often unsuccessful" (p 102). Further, because a person's beliefs relate closely to their personal identity, influencing others through argument "constitutes a significant intrusion on the autonomy of another person" ( $p$ 81). For Casey, such costs pertain not only in cases of disagreement but also when arguers and audiences antecedently agree and when audiences desire and benefit from involuntary belief change through argument.

Describing belief change as costly has a certain intuitive appeal because belief reformulation takes work and the audience's feeling of resistance to this work may suggest an intrusion. In our view, however, Casey underappreciates the complex balance of costs associated with belief change that we find create three interrelated complications for his

$\overline{4}$ We return to this point in Sect. 2.3. analysis. First, we question whether there is good reason for synchronic rather than diachronic evaluation of the costs and benefits of argument. Second, cost-benefit calculations about arguing should address how feelings provide subjective evidence of the costs and benefits of audience experience. Third, given the involuntary and indirect voluntary belief change that is ongoing for people via their reasoning and empirical engagement with the world, it seems unlikely that belief-change through argument necessarily or meaningfully increases costs beyond the status quo, particularly when that change benefits the audience.

The costs and benefits of involuntary belief change must be assessed in some temporal range because change is not instantaneous. Belief changes that occur during an argument may be relatively synchronic and may involve a straightforward and immediate cost to the audience. But most belief change occurs over longer periods and taking a diachronic perspective influences cost-benefit calculation. For example, over the long run a changed mind may help beliefs logically cohere, relieve stressful and exhausting cognitive dissonance, eliminate dangerous empirical and interpersonal misunderstandings, and avoid conflict. When arguers' interests are collaborative or cooperative such as to develop understanding and knowledge, to inquire (Bailin and Battersby 2020; Walton 1998), or to negotiate for a mutually acceptable division of goods, then the audience may use arguing to eliminate costs. Formal structures and institutions of argument may also aim to reduce costs, as in the case of legal negotiation. Whatever costs an audience might incur in cognitive change synchronically can be incidental and trivial relative to net gain diachronically. Submitting oneself to the wisdom of another's reasoning provides one of the key diachronic benefits of arguing, making it unclear that arguing emerges as necessarily costly, even on average.

One might object that the costs of synchronic belief change, considered in isolation, are clear and this is all Casey needs to show the costliness of shifting beliefs. But, even synchronically, in the time it takes to change one's mind, matters are complicated. Consider, for example, that belief changes associated with reinforcing desired beliefs feel pleasant and beneficial, and that those associated with disconfirming desired beliefs feel unpleasant and costly. The felt dimensions of belief change suggest that when an arguer provides reasons for the audience to strengthen a cherished or desired belief, or confirm an intention to act, the belief change has little or insignificant cost. It imposes no immediate cost to trace a well-travelled neuronal path again, and no significant cost accrues from adding or reinforcing a neuronal connection or two, perhaps providing a relieving reassurance or helpful presence of mind. What are beliefs if not well-trodden, well-integrated, neuronal pathways comprising feelings and cognition? To diverge from or completely rewire a pathway costs more than continuing 
with it. While feelings constitute an imperfect guide to costs and benefits, they provide all organisms with information about how they are doing, information about the costs of psychological states like belief, for humans, and information that suggests variable benefits and costs from belief change.

The third issue we wish to raise regarding the costs and benefits of arguing is that adjustments to beliefs constitute a constant condition of engaging the world. The belief changes that arise through argument may comprise but a tiny fraction of belief changes audiences experience. Moreover, belief change commonly arises in contexts of impersonal adversity, wherein "situations or circumstances work against an agent so that he or she is further away from a desired or desirable goal or state than expected" (Russell 2015, p 163). This makes it hard to see why belief changes due to argument necessarily or meaningfully increase costs for the audience beyond what they already incur in everyday life and ordinary adversity. The costs of belief change form part of the fabric of everyday psychological experience.

Seeing no clear reason to calculate the costs of argument using thin time slices, to discount what feelings indicate about the costs of belief change, or to assume that arguing affects belief in a way that is inherently, meaningfully, or distinctly costly, the door remains open for a fuller assessment of the costs and benefits of argument for audiences. Further, as we argue, contra Casey, in the next section, adversarial arguing must be a process, and a process view of it provides additional support for assessing the costs and benefits of belief change diachronically.

\subsection{Adversarial Dialectic}

Even admitting that arguers have various intentions regarding audiences, that audiences have significant agency in belief change, and that benefits of belief change may outweigh the costs, Casey could hold fast to his view that arguments are intrinsically adversarial because his view locates adversariality in the very structure of the act of arguing. Casey compares the adversarial structure of argument to competitive games:

Certain kinds of encounters are necessarily adversarial whether or not the participants want them to be so. Hockey and chess are adversarial so long as the rules are followed. This remains the case no matter how badly one side loses or fails to put in a serious effort ... Adversariality is, in other words, a state and not a process. By contrast, aggressiveness seems to admit of degree. (pp 91-92)

As in hockey or chess, the language of adversariality indicates a mutual dynamic. Arguments count as adversarial because each participant acts or is expected to act on the other. Casey contends that arguers frustrate and compel each other in argument interactions.

This account of adversarial structure, however, imposes on a moment in time-a state-certain dialectical characteristics that depend on a diachronic perspective and the involvement of processes that Casey sidelines. Consider a case in which an arguer compels an audience to believe a claim, the audience believes it, and the argument ends. The arguer has "unidirectionally" changed the beliefs of the audience and has thus advanced a successful argument. In hockey, however, the game exists only if both teams play. Analogously translating Casey's account of adversariality into the language of hockey, it would be possible to count a case wherein team A scores on team B, and team B just sits there, "scored upon", as a "game". The "unidirectional" case of arguing, the mere speech act of expressing reasons, should also be clearly adversarial, if we follow the logic in which belief involuntarism constitutes adversariality.

An adversarial orientation between arguers does not necessarily follow from the potential involuntary cognitive response that Casey correctly observes to constitute a noteworthy and neglected dimension of the sharing of reasons, even should it occur. Adversarial structures involve two dimensions of agency in a dialectic that must fall away for the influence of the arguer on the audience to appear one-dimensional and hence involuntary. In this way, Casey's interactive adversariality seems to require it both ways: synchronic insofar as the audience does not respond; and diachronic insofar as the audience might try to exert their own control over their own beliefs or the arguer's. The claim seems to be that the structure of the expression of reasons anticipates a diachronic response and makes sense only as part of a mutual dynamic.

The difficulty of conceiving argument except as diachronic suggests that the involvement of adversarial interaction must be a process rather than a state. Even if adversariality itself is not a process, the interaction of arguing that may be adversarial is. Arguments are dynamic, involving a dialectic that unfolds in time. Rarely will an open-minded audience consent for the arguer to assume control of their beliefs; typically, they need to sort out for themselves the implications of the arguer's line of reasoning. Moreover, to believe, an audience also feels that the acquired claim is true. Beliefs involve feelings of confidence, certainty, favoring, or other approbative epistemic feelings (Slote 2020) and might also be distinguished by the absence of epistemic feelings such as curiosity. Crucially, epistemic feelings such as feelings of confidence, knowing, and certainty are difficult to force or even encourage in others. The force of reasons does not remain in the arguer's control for long, if at all, and so the expression of reasons can only be adversarial in Casey's sense in very specific circumstances: those involving a tiny time-slice, minimal dialectic, and a shrewd and deliberate 
arguer who knows exactly how to change their audience's beliefs.

The structural conception of adversariality faces a further obstacle in that, pace formal dialecticians, the expression of reasons does not on its own implicate the kind of structural opposition found in games such as chess and hockey. Rules are rarely clear, certain, or even consistent in real arguing and while that instability can make it seem like a wrestling match, it remains possible to interact with another's reasons in a way that is both "one-way" and non-adversarial. Nonadversarial dimensions can be found even in "zero-sum" competitive sports because winners and losers can share certain goods of the game, such as sporting excellence and good sportspersonship (Russell 2007; Simon 2000).

Belief involuntarism may help to explain common concerns about the effects of adversarial tendencies on arguers and audiences: sometimes an arguer may push another around with their reasons. Nevertheless, the dialectical complexities of arguing show it to provide a strong exception to the general case for doxastic involuntarism. In taking the dynamic process view of argument seriously, we find that doxastic involuntarism only occasionally generates adversariality. Belief change through argument has little in common with situations wherein one cannot make themself believe that the coffee cup in their hand is a hedgehog stuffy. This process view further supports our position that audiences have greater agency and that belief change often provides more benefit than Casey allows. As we argue in Sect. 4, a clearer picture of the complexities of arguer and audience agency, and the costs and benefits of belief change, remains important if we are to identify and care for vulnerabilities in argument that may include, but are not exhausted by, adversariality.

\section{Invitational Rhetoric and Audience Agency}

Thus far, our position challenges the view that arguments must "act upon" audiences in changing their belief as well as the view that intellectual force in argument makes it necessarily adversarial. What Casey calls "adversarial interaction" interests Foss and Griffin (1995) too and yet their account of invitational rhetoric helps to build our case that even an involuntary audience's response does not make an argument adversarial by illustrating how the larger discursive dynamic influences audience response. Unlike Pinto, who uses the notion of invitation to address the nature of persuasion, Foss and Griffin advocate invitational rhetoric as an alternative to (but not a replacement for) persuasion. Pinto, Foss and Griffin do, however, use invitation to conceptualize modes of interaction in which the arguer is not the audience's adversary. ${ }^{5}$ (They landed on the same language of "invitation" coincidentally around the same time.)

Part of Foss and Griffin's concern with persuasive argument relates to the kind of issues Casey raises regarding the involuntariness of belief change. Rhetors may participate in the belief systems of the audience and either undermine or at least challenge the audience's autonomy of belief. Foss and Griffin are particularly concerned with definitions of rhetoric "as the conscious intent to change others" $(1995, \mathrm{p} 2)$ in the form of persuasion. A persuasive dynamic wherein the rhetor has influence, power, authority, and control over the audience creates problems from their feminist perspective. Audiences are vulnerable to power dynamics that influence belief involuntarism, but also to having their counterpoints silenced, to feeling forced to concede points that they disagree with, to losing confidence, and to feeling frustrated, angry, or humiliated. Foss and Griffin argue, in a way resonant with Casey, that the aspects of persuasion associated with involuntariness and compromised audience agency make arguing adversarial. However, for them, treating the rhetor as the agent of belief change in others not only challenges epistemic self-determination and self-reliance but also, from the standpoint of feminist and social epistemologies, it suggests a hyper-autonomy, excessive individualism, intrusion, and even domination.

To ward off such oppressive implications, Foss and Griffin develop an invitational alternative to persuasive argument that invokes principles of "equality, immanent value, and self-determination" for both the rhetor and audience (1995, p 5). In keeping with these principles, an invitational rhetor aims not to change and control others, but to enable and facilitate understanding of the issue and of the participants themselves. They explain:

Invitational rhetoric constitutes an invitation to the audience to enter the rhetor's world and to see it as the rhetor does. In presenting a particular perspective, the invitational rhetor does not judge or [devalue] others' perspectives but is open to and tries to appreciate and validate those perspectives, even if they differ dramatically from the rhetor's own. Ideally, audience members accept the invitation offered by the rhetor by listening to and trying to understand the rhetor's perspective and then presenting their own. When this happens, rhetor and audience alike contribute to the thinking about an issue so that eve-

\footnotetext{
${ }^{5}$ Foss and Griffin tend to conflate persuasion with argument, as is common in rhetorical scholarship on argumentation. For sake of clarity, we will use the terminology of "persuasive argument" to discuss their account, allowing that there may be non-persuasive forms of argument that are themselves "invitational" and thus for which invitational rhetoric would not serve as an alternative.
} 
ryone involved gains a greater understanding of the issue in its subtlety, richness, and complexity (p 5).

Invitational rhetoric identifies particular effects arising from respectful listening and effortful attention to another person's perspective on the world: both rhetor and audience leave the exchange with a better understanding of one another because of the "nonhierarchical, nonjudgmental, nonadversarial framework established for the interaction" (Foss and Griffin 1995, p 5). They alike learn and transform.

The invitation offered to explore the worlds and perspectives of others need be neither imposing nor adversarial. The principles that discussants follow, and the structure of the communication exchange, aim to identify and minimize "impediments to the creation of understanding" and create an environment for the "process of discovery" ( $p$ 6). There is no effort to establish one view over another or to foreclose the exchange such that one party is intact and the other changed. Moreover, Foss and Griffin explain that

[t]he internal processes by which transformation occurs also are different in invitational rhetoric. In traditional rhetoric, the change process often is accompanied by feelings of inadequacy, insecurity, pain, humiliation, guilt, embarrassment, or angry submission on the part of the audience as rhetors communicate the superiority of their positions and the deficiencies of those of the audience (p 6).

The emotional vulnerabilities associated with adversariality diminish when both the audience and the rhetor jeopardize their beliefs or worldview. They are in it together. Invitational rhetoric is thus like many other forms of communication insofar as it may or may not involve belief change just as all communication stands to change beliefs. Unless one is prepared to treat all communication as adversarial because it potentially leads to belief change- a view which dilutes the concept of adversariality to an homeopathic extreme-one must allow for differently valenced forms of communication.

Foss and Griffin stress - and Bone et al. (2008) further clarify - that invitational rhetoric cannot entirely replace persuasive argument. Rather, it provides a fully viable nonadversarial option. In addition, the invitational rhetoric approach may spill over into persuasive contexts, encouraging arguers to stress principles of equality, immanent value, and self-determination, much as arguers do when they wish to avoid ancillary adversariality through skillful management (Aikin 2011) and a focus on virtue, wisdom, and intellectual flourishing in argument (Aberdein 2020; Stevens 2016; Cohen 1995). Further, invitational rhetoric does not foreclose on the possibility that changes in belief and perspective may arise in invitational contexts. As Bone et al. (2008) explain, in invitational rhetoric the result might be change, however, agency lies in the means by which safety, value, and freedom are created not in the effort to change. Rhetors are focused on creating invitational environments (through dialogue, listening, understanding or exploring another's position or view, and/ or sharing one's own position with respect and care for the positions others might hold) and they do so by creating the conditions of safety, value, and freedom (p 446).

The creation of safety, value and freedom that they envision is both epistemological and social in nature. The invitational environment seeks to reduce vulnerability to domination and coercive belief formation and to enhance epistemic security, epistemic value, and epistemic autonomy along with their ethical counterparts. In this way, the invitational account accords with argumentation theory's emphasis on the epistemic value of respectful engagement with others' views (Rooney 2003).

An understanding of agency that rejects making the arguer the agent of change and the audience the changed object underlies the normative dimensions of invitational rhetoric. In their defense of invitational rhetoric against the criticism that it lacks agency, Bone et al. (2008) distinguish between agency understood as having the "means to act" and as causing change ( $\mathrm{p} 445$ ). They say that the

charge regarding a lack of agency and invitational rhetoric exists because, for some critics, there is no agency when no effort to change others exists ... In invitational rhetoric, the agency or the means to act includes establishing an invitational environment built on the principles of safety (others have a right to their own views), value (views different than one's own are worthy), and freedom (people have the right to make choices that work for them). (p 445)

Agency understood as having the means to act is similar to the concept of autonomy understood as a suite of capacities and skills rather than as a unitary personal characteristic that one either has or lacks (Anderson 2013). Understanding agency as including multiple means to act reveals that even cases where an audience involuntarily changes belief can involve various other means of agency available to manage, adapt, reject, avoid, or otherwise address that change. The invitational rhetoric program shows the complexity of audience agency as well as the contingency of circumstances in which the audience lies entirely vulnerable to the arguer's intent to change them.

Reasons to resist models of argument and adversariality rooted in the idea that arguers are "doing to" rather than holistically "engaging with" an audience and the context of argument include the complex forces and means of 
engagement that influence an audience's response to an argument. Audiences affect reception via both their doxastic states, including doubts and questions as well as beliefs, and their non-doxastic states, such as exhaustion, sociability, and desire, as we learn from Pinto and others. Add to that the failure of causal accounts of inference and there remains little reason to consider argument interactions necessarily adversarial. Arguers and audiences are vulnerable to each other in ways that extend beyond involuntary belief change and that may or may not include such change. We consider this an extension of Casey's and Foss and Griffin's respective positions, one that paints a more complex picture of adversarial interaction by detailing and emphasizing different sources of vulnerability.

\section{Vulnerability in Argumentation}

As arguers and audiences, we are vulnerable in many ways. We are vulnerable in a basic or ontological sense given "our corporeality, our neediness, our dependence on others, and our affective and social natures" (Mackenzie et al. 2013, p 7). We are also subject to "context-specific" or "situational" vulnerabilities that "may be caused or exacerbated by the personal, social, political, economic, or environmental situations of individuals or social groups" (Mackenzie et al. 2013, p 7). Further, as arguers and audiences, our vulnerability is universal and persistent, because all people are vulnerable in various and changing ways (Gilson 2011). As Erinn Gilson recognizes, it is not the case that only some individuals are vulnerable, as is sometimes assumed in the false dichotomies drawn between abled and disabled, healthy and ill. Nor is it the case that vulnerability is "transient" over the course of life, with periods of invulnerability only occasionally interrupted by episodes of vulnerability, as people sometimes assume (2011, p 310). Gilson maintains that vulnerability involves ambivalence: it is not "an essentially negative state tantamount to harm; when it comes to the forms that it takes and the ways it is experienced, vulnerability is neither inherently negative nor positive" (Gilson 2011, p 310). Indeed, vulnerability can be empowering when it involves "openness to being affected and affecting in turn" (Gilson 2011, p 310).

This understanding that vulnerability can be ontological or situational, and also universal, persisting, and ambivalent supports our view that vulnerability provides a comprehensive account of the impact of the logical, pragmatic, and social forces of argument that account for occasionally adversarial interaction. To sketch the power of the vulnerability account, we will make clear: first, that vulnerability better accounts than adversariality for the (doxastic and nondoxastic) personal effects that the speech act of arguing has on both arguer and audience; second, that it accounts for positive as well as negative impacts of argument interaction on those involved; third, that it enriches our understanding of how adversariality works; and fourth, that it connects the intellectual force of arguments with a normative conception of "compathetic argument" developed by Daniel Cohen and George Miller (2016).

The first way that "vulnerability" provides an improved conception of arguments as interactions concerns who arguments affect. Recall Casey's view that an arguer's influence on the audience qualifies as "a significant intrusion on the autonomy of another person" (2020, p 81) and that the audience "grants" the arguer "access to [their] belief system" (pp 98-99). In Casey's account, the arguer acts on the audience and the audience plays a limited, indirect role in their belief formation. Foss and Griffin hold a similar view of the argueraudience dynamic in persuasion, associating the audience's experience with a suite of vulnerabilities regarding their belief contents, agency, identity, and so on.

These accounts focus primarily on vulnerability in a unidirectional way, from arguer to audience, except when Casey notes that "it makes sense to speak of an arguer as heroic, beyond the literal danger of speaking, to the deeper psychological danger of putting their beliefs to the test" ( $p$ 105). Those who affect or aim to affect others also have vulnerability (Gilson 2011, p 310) and in the case of speech this involves vulnerability to being heard, to the responsibilities that come with being heard, and to the effects or implications of uptake. The universal and persistent quality of vulnerability is the first factor Gilson recognizes and, whatever purposes the argument serves, arguing involves an arguer's vulnerability to audiences: sharing reasons will succeed in the purpose of persuasion, deliberation, inquiry, negotiation, or identity formation, only in light of appropriate responses from the audience, some cognitive, others involving other attitudes, and still others behavioural. Audience response and engagement may frustrate and compel arguers in various ways, or it may support them. Additionally, any trust that an audience places in an arguer's reasoning can enhance that arguer's epistemic agency, as Cynthia Townley argues (2011). An arguer's potential loss or benefit involves vulnerability, whereas conceiving argument as an adversarial interaction primarily accounts for potential loss by the audience. These points are almost certainly recognized by theorists like Casey, Foss and Griffin, and they demand attention because reasoners may downplay or ignore their own vulnerability to change when arguing, or at any time, as Gilson argues.

To neglect how affecting others exposes one's own vulnerability may also involve willful ignorance, Gilson suggests. Assuming an implausible "closure to being affected and shaped by others" serves "in the formation of masterful self-identity". (p 319) This ideal involves a fictional belief in one's invulnerability to falsehoods and belief changes motivated by others, a view that excises the epistemic community 
with which one is actually epistemically interdependent (Fricker 2006). As a description of the arguer, it presumes a false asymmetry of vulnerability relative to the audience. While Casey does not appear to hold this false assumption, those who do would readily find Casey's position bolstering, something better avoided in our view.

The second way that focusing on vulnerability provides an improved conception of argument interaction concerns costs and benefits. Characterizing argument interaction as adversarial on the basis of involuntary belief formation focuses attention on its negative effects: persuaded or otherwise moved audiences appear to experience an unwanted or costly belief change, even if the change is ultimately beneficial to them. Casey's stress on the costliness of belief change shows how the adversarial characterization brings with it a negative orientation, even though audiences may benefit from their changed beliefs. We stress, however, that a changed belief can enable rather than diminish audience agency, and so an arguer may undercut one means of audience agency while boosting another. Becoming persuaded that a job posting might be suitable can motivate the learning and other actions to secure an improved position. The potential for such positive changes emerges from vulnerability's "ambivalent" nature (Gilson 2011, p 310) and includes the openness required for adaptation to new information, changing situations, and one another. Additionally, focusing on audience costs ignores cases wherein the arguer knows they will not persuade, as in the Cady Stanton example. Such arguers know that they are vulnerable to epistemic injustice and that the audience is vulnerable to the retention of false belief rather than being passively moved by logical force.

The ambivalence of vulnerability combined with its universality makes clear that invulnerability, strength, or imposition do not principally align with the arguer while vulnerability, weakness, or receptivity align with the audience, as might be assumed when mapping belief involuntarism in a unidirectional way from arguer to audience. Vulnerabilities, strengths and weaknesses, and agency belong to each participant in an argument.

The third reason that the concept of vulnerability enables an improved conception of argument interaction is that locating adversariality in belief involuntarism makes it easier to incorrectly assume that adversariality straightforwardly increases vulnerability while invitational rhetoric decreases it. Certainly, the forcing and compelling involved in different levels of adversarial engagement can create dangerous insecurity, as is perhaps most obvious in forms of ancillary adversariality such as aggression. But adversarial arguing can also minimize the risks of vulnerability. For example, adversariality in systems of law aims to protect defendants from the epistemic distortions, biases, and abuses of power possible in inquisitorial legal systems. Adversarial persuasion also provides protection in other contexts. Bone,
Griffin and Scholz note an example from Mark Pollock et al. (1996) of how invitational rhetoric might fail to ease or even increase the vulnerability of an audience considering suicide. Pollock et al. contend that there are some cases in which persuasive force enacts "care and love for another... to preserve that which is unique and valuable in that person..." (p 149). One imagines Stevens' virtuous adversarial arguer as "a knight for her truth" (2016, p 379)—one who rescues another from beliefs and feelings that are false and deadly.

Additionally, as Henning $(2018,2021)$ shows, adversarial argument norms may enhance agency, identity, and relationships between arguer and audience in cases wherein invitational or cooperative argument norms would not. For instance, "invitational" or cooperative norms may reflect white epistemic privilege, such as when white feminists "politely" silence or devalue disagreement coming from people who are Black, Indigenous, or Persons of Colour. Bone et al. (2008) note Dana Cloud's observation that, "from the perspective of oppressed persons, it is clear that some people and many ideas should be challenged rather than invited to perpetuate hateful rhetoric and material practices such as racial discrimination and racist rhetoric" (2004, p 3). This resembles Casey's point that by ignoring adversariality in agreement, theorists may obscure the extent to which agreement can be used to control or dominate. Moreover, adversariality can minimize the vulnerability associated with politeness if one is presumed passive or less competent in argument for reasons of racism and other forms of oppression (Yap 2020).

The fourth benefit arises from vulnerability's alignment with a normative conception of argument as compathetic (Cohen and Miller 2016). Cohen and Miller (2016) introduce the ideal of compathetic arguments as "organic unities, wholes whose values are more than the sums of their parts" ( $p$ 454). Compathetic argumentation acknowledges that the adversariality of disagreement contributes to people's experience of arguing but contends that while disagreement can be part of an argument, agreement must also be present for it to be meaningful. Further, agreement and disagreement vary by degree and kind, and so "partisans who agree, but with different degrees of commitment, can argue" (Cohen and Miller 2016, p 456). This accounts for how, in Goodwin and Innocenti's case studies of arguments for women's suffrage, the arguers do not expect to influence belief but it seems they do hope to create social pressure that will change the context in which the audience will receive future arguments. Blair notes too that even unpersuasive arguments have their uses: they may function to "reassure oneself", "show that a decision has not been arbitrarily arrived at", or "indicate the reason one has for making the claim" (2020, p 7). All such forces engage vulnerability; and coming together in 
this fashion makes sense of how sometimes the logical force holds sway and sometimes other forces prevail.

Although Cohen and Miller take all argument arising from differences to be adversarial, "for the sake of argument" they consider that assumption "worth questioning" ( $p$ 455); and, in our view, the compathetic approach can reveal the value and disvalue of both adversarial and invitational modes. It has elements in common with invitational rhetorics insofar as compathy involves genuine sharing and effort "to understand and to make oneself understood" ( $p$ 455). Moreover, it constitutes "an integrating, and unifying phenomenon, so it is anti-hierarchical and anti-authoritarian" (p 455). Compathetic argument thus seems to motivate the kind of safety, value, and "means to act" for which invitational rhetorics aspire.

Forces that operate alongside the logical forces and may compete with or complement them play roles in other holistic models of argument, such as Michael Gilbert's multi-modal account (1997). These synchronic, experiential aspects of belief change belong to vulnerability and so indicate another way that our account can address the phenomenon identified by Casey and connect it with existing models. Vulnerabilities also accommodate various roles that arguers play (Stevens 2016; Stevens and Cohen 2019) insofar as diverse roles and different arguments can involve distinct vulnerabilities depending on the context and even the relative positioning of participants over the course of an exchange of reasons. Casey's account has difficulty accommodating roles given its synchronic, structural focus. People may hold multiple roles at one time, but Casey's synchronic perspective incorporates only an actor (the arguer) and the acted upon (the audience), which makes it hard to recognize how roles shift.

The complexities of vulnerability in argument account for the occasions in which one arguer may compel or frustrate another by affecting their beliefs directly, especially in the context of a compathetic model. Compathetic, multi-modal, and role-based accounts reveal the rarity of a simple adversarial dynamic between arguer and audience as proponent and opponent, or even as purely cooperative co-reasoners or inquirers. Arguer vulnerabilities extend beyond involuntary belief change and its associated costs to include the epistemic and practical costs and benefits of argumentative openness and flexibility for arguers and audiences alike.

\section{Conclusion}

The expression of reasons may involve a powerful intellectual force and exerting that force on others can be the whole point of arguing. Arguers, however, may have different intentions and arguments may have different effects. People express reasons in light of many different purposes beside persuasion and sometimes intellectual force is beside the point. Moreover, in expressing reasons, arguers involve audiences dialectically, and do not just frustrate or compel them; and so, while arguing may have involuntary effects on the audience, the effects involve various kinds and degrees of willingness. The variable and robust exchanges that can take place between arguers and audiences demonstrate that audiences can significantly guide and even decide the effect that an argument has on them. The costs and benefits of argument unfold over time in dialectic and may continue to do so long after the communication ends. So, although Casey clearly identifies an underappreciated source of adversariality in argument and shows its importance, the ontological conclusion that argument is intrinsically adversarial does not succeed.

This is not to say that argument is intrinsically nonadversarial. While rhetorical invitation and cooperation can be involved in the exchange of reasons, that does not make arguments structurally inviting or cooperative. The potential for adversariality, invitation, or cooperation remains distinct from their realization in any given argument. That invitational rhetorics may undermine audience agency and control in some circumstances underscores further that adversariality and non-adversariality may involve encroachment on the agency of others and whether they do may depend on contextual factors extrinsic to the nature of argument itself. Characterizing argument interactions in terms of frustrating and compelling the audience, on the one hand, or in purely invitational terms, on the other, misrepresents the argument dynamic and insufficiently accounts for the complex vulnerabilities of arguers and audiences.

Arguers and audiences are vulnerable ontologically and situationally whether they exchange reasons in adversarial, invitational, or cooperative modes. The vulnerabilities include varying mixtures and degrees of epistemic coercion, bias, injustice, belief change, and psychological phenomena such as fear, stress, anger, disappointment, and recalcitrance. Vulnerability accounts for the impact of an argument on the audience and the arguer, and how that impact may or may not be valuable. The rich texture of vulnerability can even enlighten how adversarial relations arise and how they can benefit the audience. The person who loses a debate may be harmed in losing a contest yet benefit in gaining knowledge (Cohen 2013). Audiences can learn to embrace their agency and question infringements upon it. They may be situationally at risk in argument, but this vulnerability may serve as a wellspring of epistemic growth and agency. Meanwhile, arguers who open themselves in full awareness of their vulnerability to the audience also may find themselves strengthened, not weakened. An adversarial arguer may recognize their dependence on audience uptake, or perhaps their adherence to assumptions that the audience stipulates, and this may allow them to recognize and uphold their 
responsibilities to the audience. Our view thus emphasizes the array of vulnerabilities and their multipotent operation in argument. Rather than tie argument to a specific vulnerability such as the need for information, advice, or recognition, the desire to impact on people or make sense of the world, or implicated feelings, we find it more illuminating to consider the variety of vulnerabilities to which arguers and audiences are subject and how arguers use dialectic to negotiate those vulnerabilities.

There are, in our view, no adversarial dynamics at play in argument so consistent as to ground ontological claims about argument. We can, however, safely claim that arguments invoke diverse vulnerabilities, and that arguers and audiences have a wide variety of ways to address them. To understand this dimension of argument, we find that a holistic, compathetic understanding offers the necessary resources. Such an approach makes room for adversarial elementswhether rooted in doxastic involuntarism or disagreement, for invitational elements, and for the variety of intellectual, pragmatic, social, and psychological forces that pertain to arguers and audiences alike.

Acknowledgements Thanks to Jean Goodwin for help securing a source that the COVID-19 pandemic made difficult to obtain.

\section{References}

Aberdein A (2020) Eudaimonistic argumentation. In: Garssen B, Eemeren $\mathrm{F}$ (eds) From argument schemes to argumentative relations in the wild: a variety of contributions to argumentation theory. Springer Verlag, Chambridge, pp 97-106

Aikin S (2011) A defense of war and sport metaphors in argument. Philos Rhetoric 44(3):250-272

Anderson J (2013) Autonomy and vulnerability entwined. In: Mackenzie C, Rogers W, Dodds S (eds) Vulnerability: new essays in ethics and feminist philosophy. Oxford University Press, Oxford, pp 134-161

Bailin S, Battersby M (2020) Is there a role for adversariality in teaching critical thinking? Evidence, persuasion and diversity, OSSA conference archive: https://scholar.uwindsor.ca/cgi/viewcontent. cgi? article $=2468 \&$ context $=$ ossaarchive

Blair JA (2020) The persuasive ineffectiveness of arguing and arguments. Evidence, persuasion and diversity, OSSA conference archive: https://scholar.uwindsor.ca/ossaarchive/OSSA12/Friday/ $10 /$

Bone EB, Griffin C, Scholz L (2008) Beyond traditional conceptualizations of rhetoric: invitational rhetoric and a move towards civility. Western J Comm 72(4):434-462

Burrow S (2010) Verbal sparring and apologetic points: politeness in gendered argumentation contexts. Informal Log 30(3):235-262

Casey J (2020) Adversariality and Argumentation. Informal Log 40(10):77-108

Cialdini RJ (2007) Influence: the psychology of argument, revised. Harper Collins, New York

Cloud D (2004) Not invited: struggle and social change. Paper presented at the National Communication Association Convention, November 2004
Cohen DH (1995) Argument is war and war is hell: philosophy, education, and Metaphors for Argumentation. Informal Log 17(2):177-188

Cohen DH, Miller G (2016) What virtue argumentation theory misses: the case of compathetic argumentation. Topoi 35:451-460

Cohen DH (2013) For argument's sake, TED Talk (August 2013) https://youtu.be/JTN9Nx8VYtk

Doury M (2012) Preaching to the converted. Why argue when everyone agrees? Argumentation 26:99-114

Foss S, Griffin C (1995) Beyond persuasion: a proposal for an invitational rhetoric. Commun Monogr 62:2-18

Fricker M (2006) Powerlessness and social interpretation. Episteme 3(1-2):96-108

Fulkerson R (1996) Transcending our conception of argument in light of feminist critiques. Argum Advocacy 32:199-217

Gearhart SM (1979) The womanization of rhetoric. Women's Stud Inter Q 2:195-201

Gilbert MA (1997) Coalescent argumentation. Routledge, New York

Gilson E (2011) Vulnerability, ignorance, and oppression. Hypatia 26(2):308-332

Goodwin J, Innocenti B (2019) The pragmatic force of making an argument. Topoi 38:669-680

Govier T (1999) The philosophy of argument. Newport News, Vale

Henning TM (2018) Bringing wreck. Symposion 5(2):197-211

Henning TM (2021) I said what I said: black women and argumentative politeness norms. Informal Log 41(1):17-39

Hundleby C (2010) The authority of the fallacies approach to argument evaluation. Informal Log 30(3):279-308

Hundleby C (2013) Aggression, politeness, and abstract adversaries. Informal Log 33(2):238-262

Hundleby, C (2020) Epistemic coverage and argument closure. Topoi (advance on-line)

Ichino A, Räikkä J (2020) Non-doxastic conspiracy theories. Argumenta 2020:1-18

Ichino A (2015) Imagination in thought and action. Dissertation, University of Milan

Mackenzie C, Rogers W, Dodds S (eds) (2013) Vulnerability: new essays in ethics and feminist philosophy. Oxford University Press, Oxford

Nozick R (1981) Philosophical explanations. The Belknap Press, Cambridge

Pinto RC (2001) The relation of argument to inference. Argument, inference and dialectic. Kluwer Academic Publishers, Dordrecht, pp 32-45

Pinto RC (2009) Argumentation and the force of reasons. Informal $\log 29(3): 268-295$

Pinto RC (2010) The uses of argument in communicative contexts. Argumentation 24(2):227-252

Pollock MA, Artz L, Frey L, Pearce WB, Murphy BA (1996) Navigating between Psylla and Charybdis: continuing the dialogue on communication and social justice. Commun Stud 47:142-151

Rooney P (2010) Philosophy, adversarial argumentation, and embattled reason. Informal Log 30(3):203-234

Rooney P (2003) Feminism and argumentation: a response to Govier. OSSA Conference Archive, 77 https://scholar.uwindsor.ca/ossaa rchive/OSSA5/papersandcommentaries/77

Russell JS (2007) Broad internalism and the moral foundations of sport. In: Morgan WJ (ed) Ethics in Sport. Human Kinetics Publishers Inc., Champaign, pp 51-66

Russell JS, Robert L (2015) Simon on sport, values, and education. J Phil Sport 43(1):51-60

Schiffrin D (1984) Jewish argument as sociability. Lang Soc 13(3):311-335

Simon RL (2000) Internalism and internal values in sport. J Phil Sport 27(1):1-16 
Slote M (2020) Between psychology and philosophy: east-west themes and beyond. Palgrave Macmillan, Cham

Stevens K (2016) The virtuous arguer: one person, four roles. Topoi 35(2):375-383

Stevens K, Cohen D (2019) The attraction of the ideal has no traction on the real: on adversariality and roles in argument. Argum Advocacy 55(1):1-23

Townley C (2011) A defense of ignorance: its value for knowers and roles in feminist and social epistemologies. Lexington Books, Lanham

Walton D (1998) The new dialectic: conversational contexts of argument. University of Toronto Press, Toronto
Walton D (2005) Justification of argumentation schemes. Australas J Log 3:1-13

Walton D (2011) Reasoning about knowledge using defeasible logic. Argum Comput 2(2-3):131-155

Yap A (2020) Argumentation, adversariality, and social norms. Metaphil 51(5):747-765

Publisher's Note Springer Nature remains neutral with regard to jurisdictional claims in published maps and institutional affiliations. 